\title{
A risk analysis framework for forest pest management
}

\author{
by V.G. Nealis ${ }^{1}$
}

\begin{abstract}
A risk analysis framework comprised of assessment, response and communication elements is discussed in the context of forest pest management in Canada. Despite many shared pests and common issues in resource management, capacity in forest pest management varies greatly by jurisdictions depending on historical, socio-economic and cultural expectations. Research and operational expertise is separated among jurisdictions as is responsibility for native and alien pests. A risk analysis framework provides a structure for the development of common evidence-based analysis, harmonized responses and best practices. Two case studies: mountain pine beetle, a native insect, and gypsy moth, an alien invasive insect, are presented to illustrate the process.
\end{abstract}

Keywords: risk analysis, forest pest management, mountain pine beetle, gypsy moth

\section{RÉSUMÉ}

Cet article propose un cadre d’analyse du risque formé déléments dévaluation, de réponse et de communication dans le contexte du contrôle des ravageurs forestiers au Canada. Bien que plusieurs administrations partagent les mêmes ravageurs et les mêmes enjeux d'aménagement forestier, elles ne possèdent pas tous la même capacité d'intervenir en matière de gestion des ravageurs forestiers en raison des attentes historiques, socio-économiques et culturelles qui leur sont propre. L'expertise en matière de recherche et de lutte se varie aussi selon les administrations tout comme la responsabilité pour la gestion des ravageurs indigènes et exotiques. Un cadre d’analyse du risque permet aux experts d'établir une structure pour harmoniser lanalyse des faits, les interventions et les bonnes pratiques. On présente deux études de cas pour illustrer le processus: une sur le dendroctone du pin, un insecte indigène et l'autre sur la spongieuse, un insecte exotique envahissant.

Mots clés : analyse des risques, contrôle des ravageurs forestiers, dendroctone du pin, spongieuse

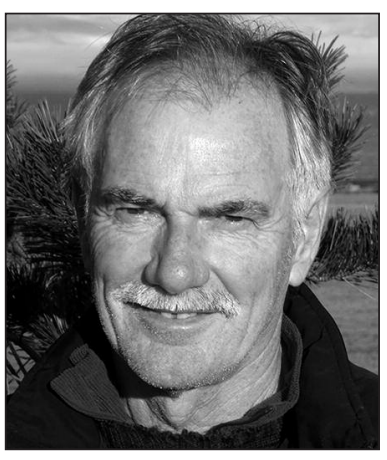

V.G. Nealis

\section{Introduction}

Outbreaks of native insects have significant ecological impacts in every major forest ecozone of Canada. These disturbances are normative drivers of change in northern forest ecosystems but also represent competition for wood fibre depending on their severity and location. Leaffeeding species such as spruce budworms, hemlock loopers and forest tent caterpillars undergo cyclical outbreaks over vast areas, causing extensive growth loss and selective mortality to their preferred host tree species. Bark-infesting species such as mountain pine beetle kill their hosts outright but the susceptibility of the trees they attack varies acutely and the relationship between beetle survival and weather is capricious so the intensity and extent of their outbreaks are often less predictable (Armstrong and Ives 1995).

Non-native or alien forest insects are more significant in the urban-forest interface. Their ecological impacts in Canada are less understood because these species are usually associated with human-modified landscapes, previously disturbed ecosystems with a different kind of ecological complexity and a different suite of socio-economic values. Native species must become noticeably abundant to have significant ecological impacts but the mere presence of alien species defines a novel impact that may result in regulatory costs (Ricciardi et al. 2013).

For the most part, whenever insects have a noticeable impact we regard it as negative and want to do something about it. This is the historical motive for pest management. With native forest insects, we intervene rarely relative to the frequency of impacts. Despite this, our interventions can be daunting in logistics and variable in efficacy and we still spend more on management of these insects than we would like. When outbreaks are extensive or remote, only a small portion of the outbreak can be treated so action must be strategic in hope of net benefits in the face of overwhelming population pressure. On the other hand, most alien species first show up as discrete infestations in our most accessible and populated areas where the dominant issues are urgency, uncertainty, and communication (Nealis 2009). In all cases we are faced with the practical challenges of playing stewards to an enormous and diverse resource, which varies by location and in time, and we do this with significant limits on available knowledge, tools and budgets.

\footnotetext{
${ }^{1}$ Natural Resource Canada-Canadian Forest Service, Pacific Forestry Centre, 506 W Burnside Road, Victoria, British Columbia V8Z 1M5. E-mail: Vince.Nealis@NRCan-RNCan.gc.ca
} 
This paper proposes a systematic application of legislation, policies and evidence to analyze threats associated with forest pests: a risk analysis framework. Risk analysis is a multidisciplinary approach to informing policy decisions in the context of threats to society and the environment at local to global scales. Although simple in concept, risk analysis can be complex in application. It nonetheless adheres to clear and consistent practices requiring accurate scoping of the problem, discovery of evidence, characterization of risk, estimation of uncertainty, identification of options, and communication with stakeholders. Risk analysis is relevant to governments as a working framework that provides a broad and consistent approach, a clear link to provisions of legislation and evidence-based policy, implemented via transparent processes. Its application to international phytosanitary measures (FAO 2005) illustrates its track record in pest management. Risk analysis can provide an effective instrument for resolution of responsibilities among stakeholders by identifying expectations and clarifying roles because it considers explicitly the social and political context for forest pest management. I first present that context for forest pest management in Canada, describe how risk analysis may be applied and then illustrate with recent examples.

\section{Forest Pest Management in Canada}

The responsibility for pest management falls normally to the landowner and most of the forest estate in Canada is owned by the public. These so-called Crown lands are managed on behalf of the public by provincial or territorial governments via legislation that enables them to license forest resources to industry and communities. But, with few exceptions, the responsibility for pest management remains with governments. Private forest ownership is smaller in volume and extent in Canada but significant nonetheless because of its concentration in areas where forestry is important. There too, the private forest owner is responsible for pest management on their land. The federal government owns little of the forest estate outside of national parks and defence lands. Since these forests are not part of the wood supply, direct insect pest management by the federal government is unusual ${ }^{2}$. Instead, federal involvement in pest management is indirect via support of the national interest in healthy forests and their relationship to employment, trade, biodiversity, registration of pesticides, and non-timber resources, including carbon balance. To that end, the federal Canadian Forest Service (CFS) assists all forest stakeholders through the provision of support in science and technology for pest management.

Alien species are peculiar because they are managed as species, not as ecological components of an owner-defined landbase. In Canada, the management of alien species is enabled by the Plant Protection Act, administered by the federal Canadian Food Inspection Agency (CFIA). This apparent clear assignment of responsibility, however, is not absolute. Once an alien species is considered established, the

\footnotetext{
$\overline{{ }^{2} \mathrm{~A} \text { recent exception is the extraction of lodgepole pine in Banff }}$ National Park to mitigate a ready pathway of mountain pine beetle into southern Alberta. Even in this case, however, there were multiple objectives that were consistent with legislation and policy in managing non-timber values such as wildlife within the park (http://www.pc.gc.ca/docs/v-g/dpp-mpb/sec5.aspx; accessed November 2013).
}

infested area is defined and may be regulated by the CFIA according to international phytosanitary agreements. Mitigation of actual impacts to the domestic ecosystem, including costs resulting from regulation, becomes the responsibility of public and private landowners; that is, the alien species are considered naturalized with respect to pest management.

This division of responsibilities among stakeholders in Canada challenges an integrated approach to pest problems. To illustrate at the broadest level, consider how the longitudinal distribution of provinces and territories in Canada is perpendicular, some would say at cross-purposes, to the latitudinal pattern of major forest ecozones (Fig. 1). Since the most significant native forest pests are associated with particular forest ecozones, jurisdictions share many outbreaks but have distinct policies and capacities to respond. If the province where an outbreak occurs first has a high tolerance for damage, its neighbours may lose the opportunity for direct, proactive response or area-wide management. Responsibilities for forest pest management become blurred when pests threaten and exceed the capacity of any one jurisdiction and impacts occur at multiple scales ranging from employment in the local forest sector to international trade.

The Canadian Council of Forest Ministers (CCFM) is a forum for cooperative initiatives among jurisdictions with common interests. In 2007, the CCFM recognized the value of a national forest pest strategy and asked a working group to identify ways to share knowledge and resources and to harmonize pest management practices for more effective results. The immediate trigger for this request was the alarming range expansion of the mountain pine beetle outbreak from British Columbia $(\mathrm{BC})$ to Alberta $(\mathrm{AB})$ but several other broad socio-economic drivers have emerged in the last few decades that recommend a review of the reasons and methods for for-

Box 1. Change and consequence for forest pest management in Canada in the past generation of forest managers

\begin{tabular}{|c|c|c|}
\hline Change & Consequence & Example \\
\hline $\begin{array}{l}\text { Changes in land } \\
\text { use and climate }\end{array}$ & $\begin{array}{l}\text { Outbreak dynamics } \\
\text { altered by change }\end{array}$ & $\begin{array}{l}\text { Mountain pine beetle } \\
\text { range expansion }\end{array}$ \\
\hline $\begin{array}{l}\text { Technology } \\
\text { creates new values } \\
\text { for trees species }\end{array}$ & $\begin{array}{l}\text { Insects on these trees } \\
\text { now regarded as pests }\end{array}$ & $\begin{array}{l}\text { Aspen as valued fibre } \\
\text { source makes tent cater- } \\
\text { pillars a concern }\end{array}$ \\
\hline $\begin{array}{l}\text { Reduced supply } \\
\text { margins }\end{array}$ & Lower tolerance for loss & $\begin{array}{l}\text { Shortfalls threaten } \\
\text { employment }\end{array}$ \\
\hline $\begin{array}{l}\text { Increased invest- } \\
\text { ment in forest } \\
\text { renewal }\end{array}$ & $\begin{array}{l}\text { Requires management } \\
\text { throughout rotation }\end{array}$ & $\begin{array}{l}\text { Emergence of seed and } \\
\text { regeneration pests }\end{array}$ \\
\hline $\begin{array}{l}\text { New forest value } \\
\text { and new } \\
\text { stakeholders }\end{array}$ & $\begin{array}{l}\text { More consultation and } \\
\text { transparency required }\end{array}$ & $\begin{array}{l}\text { Gypsy moth threatens } \\
\text { amenity value of urban } \\
\text { trees }\end{array}$ \\
\hline $\begin{array}{l}\text { Disturbance related } \\
\text { to ecological } \\
\text { sustainability }\end{array}$ & $\begin{array}{l}\text { Consider benefits of } \\
\text { disturbance by insects }\end{array}$ & $\begin{array}{l}\text { Short-term management } \\
\text { may be contrary to } \\
\text { long-term goals }\end{array}$ \\
\hline $\begin{array}{l}\text { Negotiated } \\
\text { international } \\
\text { agreements and } \\
\text { trade }\end{array}$ & $\begin{array}{l}\text { Influenced by forest } \\
\text { practices }\end{array}$ & $\begin{array}{l}\text { Loss of forest either by } \\
\text { harvest or insects affects } \\
\text { carbon balance }\end{array}$ \\
\hline $\begin{array}{l}\text { New technologies } \\
\text { (e.g., remote } \\
\text { sensing) }\end{array}$ & $\begin{array}{l}\text { More information and } \\
\text { analytical possibilities }\end{array}$ & $\begin{array}{l}\text { Decision-support } \\
\text { systems to refine and } \\
\text { track management }\end{array}$ \\
\hline
\end{tabular}




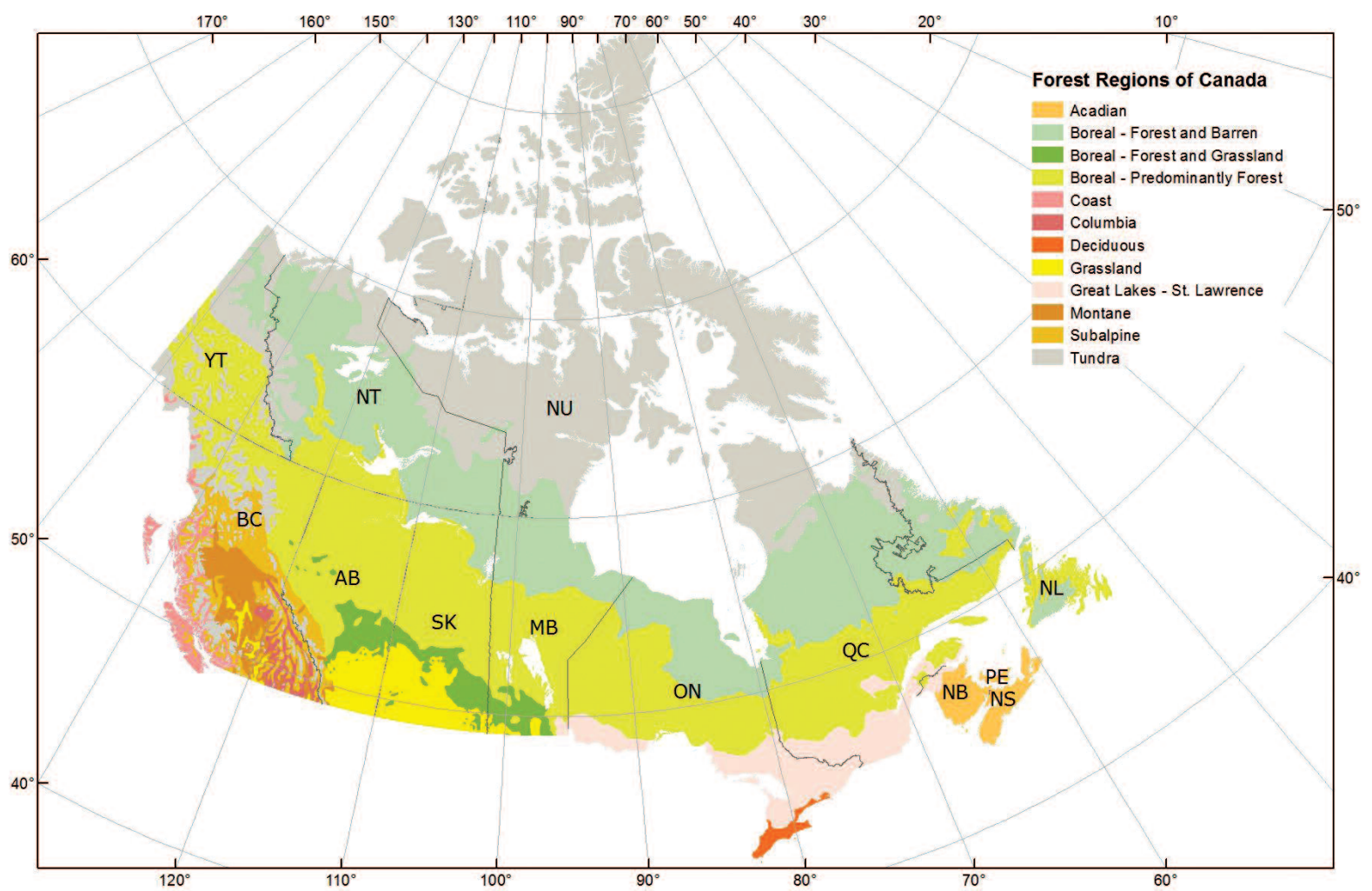

Fig.1. Forest regions, provinces, and territories of Canada (after Rowe 1972, modified by lan DeMerchant).

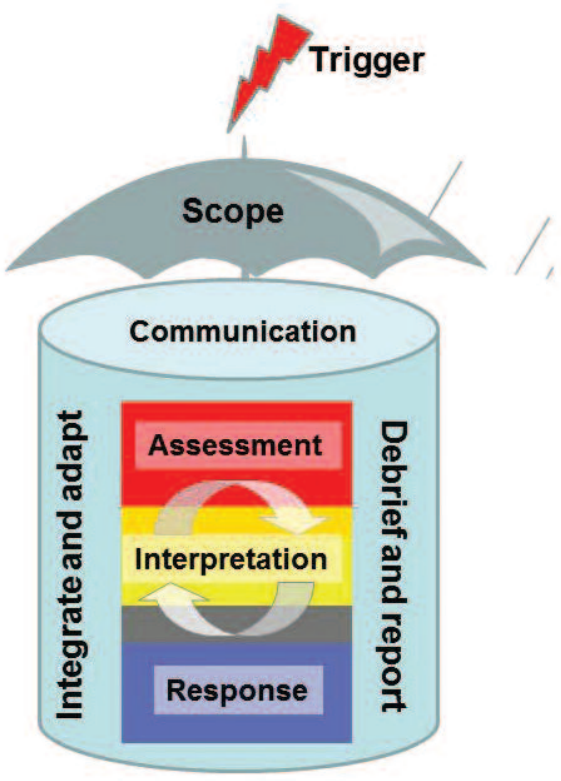

Fig. 2. Risk analysis framework. An event triggers definition of the scope of the problem. Risk assessment and response integrate evidence to characterize risk, interpret knowledge and analyze options. Communication permeates all aspects of the framework especially to foster adaptation and transparency. est pest management in the $21^{\text {st }}$ century (Box 1 ). The working group adopted a risk analysis framework as a best practise for addressing impediments and barriers to proactive, integrated pest management ${ }^{3}$.

\section{A Risk Analysis Framework}

Risk is the product of the likelihood of occurrence and the potential consequences of such an event. Risk analysis can be broadly defined to include: 1) risk assessment, 2) risk management or response, and 3) risk communication (Box 2). Risk assessment and response are technical, knowledge-based aspects of the analysis. They address the questions of "what do we know?", "what does it mean?" and "what should we do?" These two elements are at once closely linked yet necessarily separate. They are related as iterative processes with numerous points of feedback as they reciprocate exchange of information in an adaptive process. The conceptual separation between assessment and response is important as it ensures integrity and objectivity of the assessment where evidence should not be significantly influenced by cultural or economic constraints. This does not mean, however, that assessment and response cannot involve the same experts or be equally transparent. Risk communication permeates both assessment and response because it is concerned with the culture and processes of consulting stakeholders (Fig. 2).

${ }^{3}$ https://cfs.nrcan.gc.ca/pages/345 (accessed December 2013) 


\section{Box 2. Elements of a risk analysis}

Risk assessment is the overall process of hazard identification and risk estimation by explicit analysis of scientific and socioeconomic evidence to characterize, evaluate, and summarize risk in a way that addresses the specific needs of decision makers. The significance of the threat may depend on severity and cumulative impacts, temporal and spatial extent of these impacts, and whether or not these impacts are reversible.

Risk response or management evaluates those risks that warrant intervention, identifies options for response, and determines the appropriate action to manage risk. The extent to which an action is appropriate will depend on its efficacy, feasibility, and consideration of whether the response introduces new risks or exacerbates existing ones. This requires a pest management plan, decision-making process, and provision for quality control and review in relation to statutory policies.

Risk communication establishes an interactive dialogue with stakeholders to provide open and consultative decisions that are effective and clear. Although stakeholder consultation is usually regarded as pest managers communicating their plan, in risk analysis it is a two-way process. Information relevant to assessment but not available from professionals may be obtained from stakeholders and methods can be used to establish community-based estimates of risk tolerance. It is where sources of conflict resulting from different values, perceptions, and interests will emerge and as such is the forum in which the language and transparency of the technical processes of assessment and response are tested.

Risk analysis is not a substitute for pest management plans. Forest pest management plans are important policy tools that state the context, rationale, and expectations for pest management. They allow stewards to meet their obligations of reporting the status of pests, linking damage to forest inventory, identifying potential options for mitigation and operational requirements, and communicating needs in a general way. As policy tools, pest management plans could specify the application of a risk analysis framework. Alternatively, a risk analysis framework could be used to develop or adapt a pest management plan by analyzing the relative priorities for investment in, for example, monitoring or implementing alternative management regimes through application of the concept of risk.

The more common use of a risk analysis framework is in response to a specific and imminent threat. These threats may be expected, as are recurrent outbreaks of spruce budworm but when the outbreak actually occurs, its particular location, extent, and current policy and socio-economics must be analyzed before a response is implemented. Surprises, such as the discovery of an alien species like the emerald ash borer, demand even more specific analysis. The specific nature of a risk analysis as compared to a pest management plan implies the importance of defining the scope and boundaries of the intended analysis so that legislative constraints and institutional responsibilities associated with risk reduction are recognized.

As the insurance industry knows, risk and its analysis are probabilistic. People with poor driving records are more likely to have future accidents. If they also have expensive cars, the potential pay-out, or risk to the insurance company, is greater than that of a good driver in a modestly priced vehicle. The costly premium paid by the accident-prone owner of the sports car and the cheaper premium paid by the careful driver with the used sedan are the insurance company's estimate of relative risk. While the word "risk" connotes a negative outcome, classic economic risk analysis includes a consideration of benefits that might be induced by risk. This possibility should be recognized in forest pest management where disturbances by native pests are normative characteristics of forest health: the very forests we are trying to sustain are the products of previous disturbance. Interrupting those disturbances may increase future risks. For example, decades of successful fire suppression in western pine forests reduced the influence of this natural disturbance resulting in older age classes of lodgepole pine more susceptible to mountain pine beetle over a very large area. This fuelled the severity and extent of the outbreak in BC (Taylor and Carroll 2004). Thus, the short-term benefits of fire suppression incurred a longterm cost by increasing the risk from mountain pine beetle.

Risk analyses may be quantitative or qualitative or a combination of both. Quantitative analyses utilize verifiable measurements and are regarded as more objective and independent of the assessors. The insurance industry, for example, can estimate the likelihood of an accident given the driver's profile and known repair costs to calculate a sufficient premium to cover their risk. By comparison, environmental risk analyses, including those for pest management, are usually qualitative because sufficient estimates of risk, or at least important aspects such as future population behaviour, are not always available. Qualitative models, however, actually have favourable characteristics for such inherently complex systems. They are flexible in the face of insufficient data, amenable to a variety of analytical techniques, admit a range of judgements, and are more accessible to stakeholders. They can produce relative, scaled descriptions of risk that allow comparisons to tolerance for risk and establishing priorities among potential risks. Disadvantages of qualitative approaches such as the danger of ambiguity can be reduced by carefully defining the risk (likelihood and consequences) and its scope (Fig. 2). Variation among opinions of assessors or models can be reduced by external review. Nonetheless, qualitative analyses remain more prone to input bias and rigorous incorporation of uncertainty can be more problematic.

\section{Uncertainty}

Explicit estimation of uncertainty distinguishes risk analysis from most forest management plans, policies, and strategic documents. In pest management, both the likelihood and consequences of an event abound in uncertainty arising from limited information, measurement or modelling error, cultural or economic bias, system complexity, and random spatial and temporal variation. The last source of uncertainty is irreducible. The degree to which the other sources of uncertainty may be reduced is dependent on our ability to recognize them (e.g., bias and complexity) and the resources and time available to address them (e.g., information needs and errors). Equally practical is to judge how a particular uncertainty influences decisions arising from the analysis.

Popular wisdom holds that uncertainty is tolerated by science but an anathema to policy. But it is often as difficult for a scientist to recognize the uncertainty that separates discovery of a hard-won fact from its application as it is for a policy analyst to accept that a prescribed course of action could go wrong. The risk analysis framework obligates each to accept 
and communicate intrinsic uncertainty in its conclusions and decisions. Uncertainty is the property by which we judge the admissibility, relevance, and weight of evidence for the case at hand. Appeal to reasonable doubt as a criterion for decisions may be difficult for scientists in pursuit of ever-refined knowledge but should be recognized as a valid operational use of evidence. In some cases, imprecision of measurement is not that important given the objectives of the risk analysis and providing the measurement is unbiased. The level of confidence required to reject a hypothesis may not be required to inform a risk analysis usefully. Many times we must accept an opinion that is both general and of unknown accuracy because the cost of no action seems intolerable. The framework accommodates this by using diverse but relevant sources of evidence and a spectrum of experts and so relies on the empirical relationship between number of elements and confidence in the estimate. In these cases, the adaptive relationship between assessment and response to reduce uncertainty is especially critical. Perhaps more agreeable is that in demanding evaluation of uncertainty at each point in the analysis, the risk framework identifies critical knowledge gaps and so becomes a tool for adaptive management (Holling 1996).

\section{Case Studies}

A useful framework guides the focus and analysis of a problem and the processes required to implement a response. Equally useful is that it facilitates learning because each situation is sufficiently different to provide lessons (Fig. 2). Following are case studies involving mountain pine beetle and gypsy moth. Strictly speaking, neither case purposefully followed a complete risk analysis. But debriefing the history of a pest management policy and practise via a risk analysis framework is just another use of this tool to improve the approach to future pest problems.

\section{Range expansion by the mountain pine beetle Background}

The mountain pine beetle is a native bark beetle of western North America that attacks and kills most species of pine within its geographic range (Safranyik et al. 2010). The most recent outbreak accelerated in the late 1990s and became the most intense and extensive outbreak on record. By 2006, more than nine million ha of pine forests in $\mathrm{BC}$ were affected (Westfall 2006). National and scientific attention, however, soon shifted to central $A B$, east of the continental divide and outside the historic range of the beetle. Massive flights of beetles, presumably originating from outbreaks in BC, were observed throughout the late summer of 2006 and by 2007 the extent of tree mortality resulting from colonization of $\mathrm{AB}$ became apparent. This was the trigger for an emergency risk assessment. The question was whether this was a transient spill-over of outbreak populations from the west or was there now a persistent and significant threat from mountain pine beetle over a much larger part of the boreal and eastern pine forests?

\section{Scope and boundaries}

The scope of the initial risk assessment was the threat posed by range expansion by the mountain pine beetle to boreal and pine forests in Canada east of the continental divide. This specific scope was useful in defining more accurately the values at risk and the spatial scale at which the assessment should be conducted. An important boundary was the very brief time frame available so the assessment was restricted to current evidence and knowledge; no new analysis or models would be tested. Another explicit boundary was the request for an assessment only. The federal government would provide a scientific and economic assessment for jurisdictions to consider their own responses.

\section{Emergency risk assessment (2007)}

Two facilitated, round-table workshops examined first the scientific evidence with regard to the likelihood of mountain pine beetle continuing to expand its range and the resulting ecological and socio-economic impacts. A summary of these discussions was then presented as affirmative statements to a panel of five experienced specialists. For each statement, evidence solicited from the workshops was examined and supplemented where possible. Statements were sometimes slightly modified to more adequately reflect the emerging interpretation of evidence. An estimate of uncertainty from nil to very high was assigned to each statement by consensus. The results of this were then circulated to all workshop participants for review.

The method of using affirmative statements was novel and effective. Compared to questions, statements provoke trained sceptics, especially scientists, to ask, "Is that true?" Evidence is more forthcoming and its veracity weighed because there is a specific interpretation in view. This shaped the impression of uncertainty as well as identified the sources of that uncertainty. Once statements and their associated uncertainties were resolved, they provided a clearer and more decisive way to present conclusions to other assessors and especially to stakeholders.

For example, at the outset, expert consensus was there had been range expansion and until recently mountain pine beetle had never lived in the region east of the continental divide. This was a critical premise because if the alternative was true and mountain pine beetle was resident but rare and only now erupting to noticeable levels, the response options would differ immensely. We have successfully eradicated or at least slowed the spread of an alien insect species but we would never plan or hope to extirpate a resident native species, even a bark beetle. This was also a point of uncertainty raised by sceptics suspicious of the promotion of mountain pine beetle as a native insect that had become invasive with implications for spending priorities and responsibilities. So, objective evidence to substantiate expert opinion was sought. It was found in the known distribution of outbreaks in BC (Safranyik et al. 2010) and more directly in the absence of positive records for the infested area from more than 60 years of data of the Forest Insect and Disease Survey (Nealis and Peter 2008). Accordingly, we were able to provide a clear, affirmative statement "There has been a recent change in the geographic range of mountain pine beetle in Canada. Mountain pine beetle has invaded a susceptible portion of the Boreal Plains ecoregion". And because of the evidence, we were able to qualify this statement with very low to moderately low uncertainty succinctly supported by historical maps (Nealis and Peter 2008). This uncertainty has decreased further with subsequent genomic analysis that links $\mathrm{AB}$ populations to those in central BC (Samarasekera et al. 2012).

Overall, the risk assessment concluded there were few biological or ecological impediments to mountain pine beetle 
persisting in its novel range and continuing to spread. Impacts were more uncertain but the lower volumes of pine in the boreal forest suggested impacts would be moderate compared to BC. Spread rates toward high-value pine forests in eastern Canada were expected to be slower in the boreal region as a result of both forest structure and reduced density of beetles in source populations (Safranyik et al. 2010). Meanwhile, pine volumes east and north along the continental divide in the areas immediately adjacent to source populations were substantial so impacts and spread in these areas were all too evident. The most-affected province of $\mathrm{AB}$ responded with its Healthy Pine Strategy ${ }^{4}$ aimed at containment of the beetle via a zoning tactic for treatments, essentially cut and burn infested trees. There was a leading edge zone where zero-tolerance might still be feasible and an inactive holding zone where unfavourable conditions for the beetle would hopefully mitigate further population increase and spread. This management response required the province to recruit personnel to monitor and treat spot infestations, and so the province was able to increase its capacity for forest pest management significantly. $\mathrm{AB}$ also began a risk communication program with publication of specific pest management plans and extended information exchange to surrounding jurisdictions at risk ${ }^{5}$.

\section{Debrief}

The emergency risk assessment was successful in providing a timely, inclusive, and focussed science-based response. The report (Nealis and Peter 2008) was used as a communications tool by forest health professionals across Canada to brief their ministers, inform media, and develop pest management plans with respect to mountain pine beetle. However, significant improvements in a climate suitability model, considered an important advance of the risk assessment by researchers (Safranyik et al. 2010), were not widely adopted for operational purposes. The assessment also was less successful in motivating the forest management community to address critical gaps revealed by the analysis of uncertainty. Aside from those jurisdictions at most immediate threat to mountain pine beetle, roles and responsibilities remained ambiguous because there was no collective consideration of response options.

\section{Reassessment (2011)}

A second long-distance dispersal of beetles accelerated range expansion in 2009 and resulted in confirmation of successful attacks on jack pine (Cullingham et al. 2011). This triggered a request from the CCFM for a reassessment. The scope, determined by assessors from the CFS, AB, and Saskatchewan (SK), was no longer to determine if mountain pine beetle would persist in its expanded range but to examine more closely rates of dispersal and spread and associated change in fire risk. Economic consequences were not reconsidered, in part because conventional forestry values were less significant in the area of interest. Otherwise, the reassessment used the same methodology as the original assessment of facilitated workshops, resulting in affirmative statements supported by objective evidence and estimates of uncertainty.

\footnotetext{
${ }^{4}$ http://www.mpb.alberta.ca/AlbertasStrategy/Default.aspx

${ }^{5}$ http://www.mpb.alberta.ca/AlbertasStrategy/documents/MPB_ action_plan.pdf
}

Most of the biological predictions of the original assessment were confirmed by the reassessment. Improved surveillance information showed mountain pine beetle had spread more than $400 \mathrm{~km}$ both east and north since 2007. Validation of the climate suitability model decreased uncertainty that weather conditions in the new range had become more suitable for mountain pine beetle in recent decades and there was increased evidence that weather would be a significant predictor of future population behaviour (Nealis and Cooke 2014). For example, northward spread into the Northwest Territories by 2012 but not into pine-rich Yukon Territory was consistent with expectations of the earlier climate suitability models (Safranyik et al. 2010).

The reassessment also concluded that as long as there were high-density source populations, the potential for long-distance dispersal of large numbers of beetles made prediction of future spread rates uncertain. New survey results made it apparent that the sparser pine component in forests east of the continental divide was less of an impediment to spread rate than hoped as relatively isolated clusters of pine were discovered and successfully attacked by beetles. Interestingly, fire scientists still concluded that fire risk was not significantly increased as a result of mountain pine beetle impacts because these pine forests in continental climates were already prone to wildfire. There was added uncertainty to this statement, however, because there was little experience with beetleaffected pine forests in the boreal as there was for such forests in the historical range (Nealis and Cooke 2014).

Following the reassessment, $\mathrm{AB}$ convened a risk communications workshop inviting industry and government executives as well as forest health professionals. A plenary session brought all participants up to speed on the situation. This was followed by separate workshops to discuss policy options and operational practices with respective groups. Direct cooperation between jurisdictions increased with the government of SK funding monitoring and control in $\mathrm{AB}$ and YT carrying out their own surveillance in adjacent BC. Yukon Territory also held a risk communication workshop with First Nations focussed on non-timber values.

\section{Maintaining gypsy moth-free environments Background}

The gypsy moth is alien to North America. It was introduced to the northeastern USA in the late $19^{\text {th }}$ century and became established in eastern Canada by the 1970s (Nealis 2002). It has a wide host range, including many hardwoods widely distributed in Canada and valued as commercial and amenity species. By the end of the $20^{\text {th }}$ century, gypsy moth had invaded and become established in most of its climatically suitable range in eastern Canada from the Great Lakes to the Atlantic coast (Régnière et al. 2009). Recurrent introductions outside this regulated zone occurred west of the Great Lakes but the insect is not established there, in part as a result of repeated eradication programs (Nealis 2009).

\section{Scope}

In western Canada, BC has a policy of maintaining gypsy moth-free status, as it considers the economic and environmental costs of permanent infestation by gypsy moth unacceptable. Gypsy moth management in BC has been evolving for more than 30 years since the original introduction and eradication programs in the late 1970s (Nealis 2009). What 
started as a poorly communicated, technically focussed program driven by legislation is now an effective and transparent pest management plan rigorous enough to address international phytosanitary requirements but flexible enough to satisfy domestic social concerns that plagued the program from the beginning. Summarizing progress through the use of the risk analysis framework makes lessons learned useful for other cases.

\section{Risk analysis}

The technical means to detect, delimit, and eradicate gypsy moth were available and the consequences of permitting establishment in terms of ecological and regulatory impacts well known in the late 1970s. In other words, risk assessment and response were relatively advanced. The critical missing ingredient was risk communication and the result was a history of acrimony that cost both federal and provincial governments in many ways and actually increased the risk of invasion at times. The most important lesson from the gypsy moth in the context of the risk analysis framework was that, as authorities improved their communications, they also improved their capacity for technical assessments and increased their response options. Such is the value of integrated programs.

The first significant change in risk communication was the realization that technical decisions backed by legislative authority were not sufficient. Forceful application of legislative authority such as suspension of hearings and Orders in Council for aerial spays over urban centres in the face of public protest $(1992,1999)$ were not sustainable. The ill-fated use of a legislative instrument, environmental assessment hearings, as a mechanism for risk communication ultimately led to a crisis in 1999 when the federal government abruptly changed its response option from eradication to regulation, putting major forest product shipping areas under quarantine and leaving the province scrambling to implement its own eradication plans.

Positive change in risk communication lurched ahead, ironically propelled by environmental appeal board hearings increasingly critical of the government's response to previous requests. The role of an expert panel, the Gypsy Moth Technical Advisory Committee, was consolidated and an explicit, decision-making protocol developed consistent with international requirements but cognizant of historical evidence of risk in BC. Recommendations both for action and improvements to the assessment process flowed directly to decision-makers in federal and provincial governments. Knowledge-based technologies such as climate suitability models were developed so that surveillance could be targeted and spray applications timed more precisely, improving efficacy while reducing environmental exposure (Nealis et al. 2001). Public health studies on spray exposure were carried out and alternative response options including community-based egg-mass searches and mass trapping of adults evaluated (Nealis 2009). Accelerated development of a more publicly acceptable formulation of the bacterial insecticide Btk was requested by the public, promoted by government, and satisfied by industry.

The gypsy moth case study evolved, adapted and improved because it was challenged to communicate. The distinct elements of risk assessment, response and communication really are three legs of the stool and each reinforces the others.

\section{Conclusions}

At the highest level of planning, pest management programs are similar throughout Canada in that they involve the same socio-economic objectives and are implemented by governments operating under similar legislative and logistic constraints. At the specific level too, many jurisdictions share the same threats. But the commonalities among jurisdictions in pest management diverge at implementation because of differences in the economic drivers and stage of development and capacities for management of their respective forestry sectors, even though all are part of the same global fibre market and collectively represent Canada's forest-based natural resources. A common framework for assessing and responding to threats to these resources would create a modern context within which expertise and associated support could be shared, research priorities identified and funded, and management practices from surveillance methodology to strategic planning and control efficacy harmonized.

The illustrated case studies provide retrospective lessons in the utility of a risk analysis framework. Failure of effective risk communication hampered the development of an effective pest management plan for gypsy moth. By comparison, proactive implementation of risk communication in the mountain pine beetle situation fostered collaboration and created an on-going demand for information updates requiring response from forest health practitioners and scientists. However, a restricted capacity for more innovative response options revealed critical limitations to our knowledge of its population behaviour. Outside of a framework, these seem like failures. Inside a framework, they identify valuable lessons.

One of the first valued outcomes of developing a risk analysis framework within the National Forest Pest Strategy was convergence to a common lexicon. This gain is more than semantic. Pest management, by its nature, is carried out by specialists with their own vocabularies. Entomologists and pathologists must interact with operational experts ranging from unit foresters to pesticide applicators. All must understand and communicate with policy analysts, decision-makers and the public and so the first objective of a coordinating framework is to provide common reference points. A language that reflects the framework is a tangible starting point for problem-solving irrespective of the situation and diversity of participants.

The risk analysis framework also sets standards for evidence and uncertainty. This may at first seem an intimidating prospect to decision-makers faced with so many unknowns and so little time. In fact, it is a boon because it uses the clear and logical requirements of the framework to organize the basis for either action or inaction. This enables decision-makers to proceed iteratively as risk or information pertaining to that risk changes. Most importantly, the dynamics enabled by the framework requires constant engagement between information and decisions. It is a greater risk to proceed on imperfect evidence if you make no attempt to improve the evidence or are reluctant to evaluate a costly response that appears to fall short of its objective. If your pest management plan has not changed, maybe hanging it on a risk analysis framework would suggest attractive, updated alterations. 


\section{Acknowledgements}

Barry Cooke’s intelligent prodding and incisive analysis has instructed my thinking about risk from the beginning. Kevin Porter and members of the National Forest Pest Strategy Technical Committee have been tireless sounding boards. Russ Cozens and Peter Hall, now retired from BC Ministry of Forests, took refreshing risks as pest managers.

\section{References}

Armstrong, J.A. and W.G.H. Ives (eds.) 1995. Forest Insect Pests in Canada. Fo24-235/1995E, Natural Resources Canada, Ottawa.

Cullingham, C.I., J.E.K Cooke, S. Dang, C.S. Davis, B.J. Cooke and D.W. Coltman. 2011. Mountain pine beetle and host-range expansion threatens the boreal forest. Molecular Ecology 20: 2157-2171.

[FAO] Food and Agriculture Organization of the United Nations. 2005. Pest risk analysis for quarantine pests, including analysis of environmental risks and living modified organisms. International Standards for Phytosanitary Measures, Publ. No. 11. Secretariat of the International Plant Protection Convention, FAO, Rome.

Holling, C.S. 1996. Surprise for science, resilience for ecosystems, and incentives for people. Ecological Applications 6: 733-735.

Nealis, V.G. 2002. Gypsy moth in Canada: case study of an invasive insect. In R. Claudi, P. Nantel, E. Muckle-Jeffs (eds.). Alien Invaders in Canada's Waters, Wetlands, and Forests. pp. 151-159. Natural Resources Canada, Cat . no. Fo42-329/2002E.

Nealis, V.G. 2009. Still invasive after all these years: keeping gypsy moth out of British Columbia. For. Chron. 85: 593-603.

Nealis, V. and B.J. Cooke. 2014. Risk assessment of the threat of mountain pine beetle to Canada's boreal and eastern pine forests. Canadian Council of Forest Ministers. Ottawa. 27 p.

Nealis, V. and B. Peter. 2008. Risk assessment of the threat of mountain pine beetle to Canada's boreal and eastern pine forests. Information Report BC-X-417. Natural Resources Canada, Victoria, BC. 31 p.
Nealis, V., J. Régnière and D. Gray. 2001. Modeling seasonal development of the gypsy moth in a novel environment for decision support of an eradication program. In A.M. Liebhold, M.L. McManus, I.S. Otvos and S.L.C. Fosbrooke (eds.). Proceedings: integrated management and dynamics of forest defoliating insects; 1999 August 15-19, Victoria, BC. pp. 125-132. USDA For. Serv. Gen. Tech. Rep. NE-277, USDA Forest Service, Newtown Square, PA.

Régnière, J., V. Nealis and K. Porter. 2009. Climate suitability and management of the gypsy moth invasion into Canada. Biological Invasions 11: 135-148.

Ricciardi, A., M.F. Hoopes, M.P. Marchetti and J.L. Lockwood. 2013. Progress toward understanding the ecological impacts of nonnative species. Ecological Monographs 83: 263-282.

Rowe, J.S. 1972. Forest Regions of Canada. Department of the Environment, Publication No. 1300. 172 p.

Safranyik, L., A.L. Carroll, J. Régnière, D.W. Langor, W.G. Riel, T.L. Shore, B. Peter, B.J. Cooke, V.G. Nealis and S.W. Taylor. 2010. Potential for range expansion of mountain pine beetle into the boreal forest of North America. The Canadian Entomologist 142: 415-442. Samarasekera, G.D.N.G, N.V. Bartell, B.S. Lindgren, J.E.K. Cooke, C.S. Davis, P.M.A. James, D.W. Coltman, K.E. Mock and B.W. Murray. 2012. Spatial genetic structure of the mountain pine beetle (Dendroctonus ponderosae) outbreak in western Canada: historical patterns and contemporary dispersal. Molecular Ecology 21: 2931-2948.

Taylor, S.W. and A.L. Carroll. 2004. Disturbance, forest age, and mountain pine beetle outbreak dynamics in BC: a historical perspective. In T.L. Shore, J.E. Brooks and J.E. Stone (eds.). Mountain Pine Beetle Symposium: Challenges and Solutions, October 30-31, 2003, Kelowna, BC. pp. 41-51. Information Report BC-X-399. Natural Resources Canada, Victoria, BC.

Westfall, J. 2006. 2006 Summary of forest health condition in British Columbia. Pest Management Report Number 16. Victoria, BC. 